\title{
Gold nanoparticles stabilize peptide-drug-conjugates for sustained targeted drug delivery to cancer cells
}

\author{
Kalishwaralal Kalimuthu', Bat-Chen Lubin ${ }^{1,2}$, Andrii Bazylevich³, Gary Gellerman³, Ofer Shpilberg ${ }^{4}$, \\ Galia Luboshits ${ }^{1}$ and Michael A. Firer ${ }^{1,5^{*}}$
}

\begin{abstract}
Background: Peptide-drug-conjugates (PDCs) are being developed as an effective strategy to specifically deliver cytotoxic drugs to cancer cells. However one of the challenges to their successful application is the relatively low stability of peptides in the blood, liver and kidneys. Since AuNPs seem to have a longer plasma half-life than PDCs, one approach to overcoming this problem would be to conjugate the PDCs to gold nanoparticles (AuNPs), as these have demonstrated favorable physico-chemical and safety properties for drug delivery systems. We set out to test whether PEG coated-AuNPs could provide a suitable platform for the non-covalent loading of pre-formed PDCs and whether this modification would affect the bioavailability of the PDCs and their cytotoxicity toward target cancer cells.
\end{abstract}

Methods: Peptides specifically internalized by A20 murine lymphoma cells were isolated from a phage library displaying 7 mer linear peptides. Peptide specificity was validated by flow cytometry and confocal microscopy. PDCs were synthesized containing a selected peptide (P4) and either chlorambucil (Chlor), melphalan (Melph) or bendamustine (Bend). Gold nanoparticles were sequentially coated with citrate, PEG-6000 and then PDC (PDC-PEG-AuNP). The physico-chemical properties of the coated particles were analyzed by electrophoresis, TEM, UV-VIS and FTIR. Stability of free and PDC-coated AuNP was determined.

Results: Biopanning of the phage library resulted in discovery of several novel peptides that internalized into A20 cells. One of these (P4) was used to synthesize PDCs containing either Chlor, Melph or Bend. All three PDCs specifically killed A20 target cells, however they had short half-lives ranging from 10.6 to $15.4 \mathrm{~min}$. When coated to PEG-AuNPs, the half-lives were extended to 21.0-22.3 h. The PDC-PEG-AuNPs retained cytotoxicity towards the target cells. Moreover, whereas pre-incubation for $24 \mathrm{~h}$ of free PDCs almost completely abolished their cytotoxic activity, the PDC-PEGAuNPs were still active even after $72 \mathrm{~h}$ pre-incubation.

Conclusions: Peptide-drug-conjugates hold potential for improving the target efficacy of chemotherapeutic drugs, however their short half-lives may limit their application. This hurdle can be overcome by easily conjugating them to gold nanoparticles. This conjugation also opens up the possibility of developing slow release formulations of targeted drug delivery systems containing PDCs.

Keywords: Targeted drug delivery, Peptide drug conjugates, Phage display, Gold nanoparticles

\section{Background}

Efficient systems for the targeted delivery of drugs into cancer cells have not yet reached the clinic. These

\footnotetext{
*Correspondence: firer@ariel.ac.il

1 Dept. Chemical Engineering, Ariel University, 40700 Ariel, Israel

Full list of author information is available at the end of the article
}

systems are important to develop because their potential to minimize off-target side effects may lead to a significant widening of the therapeutic window. However to achieve this goal it will in part, be necessary to improve the stability of the carrier-drug constructs so as to ensure restricted release of the drug payload to the tumor cell or at least its local environment. 
The strategy of targeted drug delivery (TDD) to tumor cells is based on cell surface heterogeneity between normal cells and cancer cells. For example the targeting of over expressed receptors by high affinity biomolecular carriers such as antibodies can mitigate the selectivity problems of chemotherapy [1]. However, despite the accelerated clinical development of antibody-drug-conjugates, there remain a number of challenges to their efficient use [1,2]. Our research focus is to use much smaller carriers such as peptides and we have demonstrated that such peptide-drug-conjugates (PDCs) are not only specific for their target cells, but they do not induce outgrowth of drug resistant cells, can reverse drug resistance and can deliver multi-drug payloads [3-8].

One of the remaining challenges to the successful application of PDCs for cancer therapy is the relatively low stability of peptides to enzymatic hydrolysis in the blood, liver and kidneys [9]. One approach to overcoming this problem would be to conjugate the PDC to nanoparticles, as these have demonstrated improved pharmacokinetic and pharmacodynamics properties when used as drug delivery systems [10, 11]. Indeed gold nanoparticles (AuNPs), with their favorable physico-chemical and safety properties $[12,13]$ and ease of synthesis [14] might be appropriate agents for enhanced PDC delivery. Similar to organic colloids, ligand modification is not necessary for chemiadsorption on to the colloidal gold surface, so AuNPs can easily be conjugated to different molecules such as peptides, enzymes, DNA and small molecule drugs [15] and can lead to improved drug stability and reduced side effects $[16,17]$. Unfortunately, despite the huge amount of research being conducted in applying nanoparticles to cancer therapy (7174 Web of Science entries for 2016 alone), a recent 10-year literature analysis by Wilhelm et al. showed that overall, only about $0.7 \%$ of the administered dose of nanoparticles actually reach a solid tumor $[18,19]$.

Since AuNPs seem to have a longer plasma half-life than PDCs, we thought to use them not as a drug delivery mechanism but rather as a PDC stabilizer. We hypothesized that PDCs conjugated to AuNPs may improve the former's bioavailability. We set out to test whether PEG coated-AuNPs could provide a suitable platform for the non-covalent loading of pre-formed PDCs and whether this modification would affect the bioavailability of the PDCs and their cytotoxicity toward target cancer cells.

\section{Methods}

\section{Cell culture}

The primary normal cells HMVEC-dBlAd-Adult dermal blood microvascular (CC-2811) and human renal proximal tubule cells-(CC2553) were purchased from Lonza (Switzerland) and grown in EGM 2MV bullet kit-(cc4147), and REGM bullet kit-(cc3191) media respectively, as recommended by the supplier. 3T3 mouse fibroblasts, human HL-60, NB4 and murine A20 leukemic cells (purchased from ATCC) were grown in RPMI 1640, 10\% FBS, antibiotics and $2 \mathrm{mM}$ L-glutamine (Biological Industries, Bet Haemek, Israel). Mouse MOPC 315.BM cells (kindly provided by Prof. Bjarne Bogen; University of Osla, Norway) were grown in RPMI 1640 GlutaMAX (Gibco) supplemented with 1\% MEM NEAA 100× (Gibco), 1\% sodium pyruvate (Gibco), $0.005 \% 1 \mathrm{M}$ I-thioglycerol (Sigma), 0.03\% Gensumycin $40 \mathrm{mg} / \mathrm{ml}$ (Sanofi Aventis) and $10 \%$ Fetal Bovine Serum (Gibco). Cells were cultured at $37^{\circ} \mathrm{C}$ in $5 \% \mathrm{CO}_{2}$ and passaged at 3- to 4-day intervals at sub-confluency. Murine cell suspensions of heart and kidney were prepared from Balb/c mice by mincing the tissue into PBS. The suspension was passed through a $70 \mu \mathrm{m}$ mess and the cells washed thrice in PBS.

\section{Removal of irrelevant phage clones by in vitro negative selection}

To remove non-relevant phage clones before exposure to the target cells, a linear heptapeptide phage display library (Ph.D.-7L New England Biolabs, MA, USA) was sequentially exposed to a series of normal, control cells in the following order: HUVEC, 3T3, murine heart cell suspension, murine kidney cell suspension, human peripheral blood mononuclear cells, human erythrocytes.

In each case, $1 \times 10^{6}$ log-phase cells were washed gently with PBS and re-suspended in $1 \mathrm{ml}$ of RPMI. 10 microliters of phage particles $\left(2 \times 10^{11}\right)$ were added $1 \mathrm{ml}$ of cell suspension and the mixture was incubated for $1 \mathrm{~h}$ at $37^{\circ} \mathrm{C}$ with gentle shaking. The mixture was then centrifuged at $1500 \mathrm{rpm}$ and the supernatant containing the unbounded phage was collected. A small portion $(3-5 \mu \mathrm{l})$ was retained and titrated to determine the decrease in phage titer resulting from each absorption. The remainder was used for the next stage of negative panning. The library was similarly exposed to matrigel. After the final absorption, the resultant negatively selected phage pool was termed "adsorbed phage library".

\section{Positive selection for A20 internalized phage peptides}

A20 cells $\left(1 \times 10^{6}\right)$ were incubated with the adsorbed phage library for $1 \mathrm{~h}$ at $37{ }^{\circ} \mathrm{C}$ with gentle shaking. The mixture was then centrifuged for $5 \mathrm{~min} 14,000 \mathrm{rpm}$, the supernatant was discarded and the cells washed with PBS. They were then incubated for $10 \mathrm{~min}$ with $200 \mu \mathrm{l}$ of $0.1 \mathrm{M} \mathrm{HCl}$ ( $\mathrm{pH}$ 2.2) to elute cell surface-bound phage. This recovered solution was immediately neutralized by addition of $30 \mu \mathrm{l}$ $0.5 \mathrm{M}$ Tris ( $\mathrm{pH} 9$ ). The cells were then lysed for $1 \mathrm{~h}$ on ice in $200 \mu \mathrm{l}$ of $30 \mathrm{mMTris}-\mathrm{HCl}$ and $1 \mathrm{mM}$ EDTA (pH 8.0) to recover the cell-internalized phage fraction. After titration of this lysate, 10-15 isolated plaques were individually recovered, amplified and their DNA extracted according the library manufacturer's instructions. Peptide inserts 
were sequenced by Sanger sequencing (Hylabs, Israel) using primers supplied by New England Biolabs and peptide amino acid sequences were deduced.

\section{Peptide synthesis}

Peptides were synthesized using solid phase synthesis either as free peptides or conjugated at the $\mathrm{N}$-terminus to FITC (China Peptides Co., Ltd, Shanghai, China). The products were purified ( $>95 \%)$ by HPLC and characterized by mass spectrometry.

\section{Specificity of peptide binding}

To assess the binding capacity of the candidate peptides, peptide-FITC conjugates were incubated at 0,4 or $8 \mu \mathrm{M}$ with $10^{6} \mathrm{~A} 20$ cells at $37{ }^{\circ} \mathrm{C}$ for $30 \mathrm{~min}$. Following two washings with PBS, the cells were re-suspended in 200 $\mu \mathrm{l}$ of PBS and analyzed for peptide binding on a Becton Dickson FACS Calibur cell analyzer equipped with an argon ion laser $(15 \mathrm{~W})$ at $488 \mathrm{~nm}$ with a $530 / 30 \mathrm{DF}$ filter. For each sample $\sim 10^{4}$ cells were processed. FlowJo software was used to analyze the collected data. Peptides demonstrating the strongest binding were then tested for binding specificity by exposure (using the same conditions as above) to the following cells: mouse peripheral mononuclear cells (PBMC), murine MOPC 315.BM and the human leukemic cell lines (HL-60 and NB-4).

\section{Confocal microscopy}

A20 cells $\left(10^{5}\right.$ cells/well) were plated into 8 chamber glass slides and then incubated with FITC-peptide conjugates $(8 \mu \mathrm{M})$. After $30 \mathrm{~min}$ of incubation, intracellular distribution of the fluorescence was analyzed using a Zeiss confocal microscope (LSM 510 Meta) equipped with a NA $1.4 \times 63$ oil-immersion Plan-Apochromat objective lens. After counterstaining of cells with DAPI, fluorescent images of tissue slides were acquired.

\section{Synthesis of peptide-drug conjugates (PDC)}

Peptides P-4 and P-6 bound to 2-chlorotrityl resin (Additional file 1: Figure S1) were supplied by PepMic Co., Ltd, China. Drugs (Chlorambucil, Melphalan and Bendamustine) and other chemicals and solvents were purchased from Sigma-Aldrich (Rehovot, Israel). N-Boc melphalan was prepared by the method described by Xu et al. [20] and conjugated to the peptide via standard Fmoc-SPPS procedures. The solid phase based synthesis of peptide- Chlorambucil and Bendamustine PDC was performed by following a previously described procedure [21] The peptide-drug-conjugate were cleaved from resin using 95\% TFA 5\% DCM mixture, purified on preparative HPLC and dried by lyophilization.

LC/MS analyses were performed on an Agilent Technologies 1260 Infinity (LC) 6120 quadruple (MS) with an Agilent SB-C18 column, $2.1 \times 50 \mathrm{~mm}$, column temperature
$50{ }^{\circ} \mathrm{C}$, eluent water-acetonitrile $(\mathrm{ACN})$ that contained $0.1 \%$ of formic acid. HPLC purifications were carried out on an ECOM preparative system, with dual UV detection at 254 and $230 \mathrm{~nm}$. Phenomenex Gemini ${ }^{\circledR} 10 \mu \mathrm{m} \mathrm{RP} 18110 \AA$, LC $250 \times 21.2 \mathrm{~mm}$ column was used. The column was kept at $25^{\circ} \mathrm{C}$. Eluent A $(0.1 \%$ TFA in water) and B $(0.1 \%$ TFA in $\mathrm{ACN}$ ) were used. A typical elution was a gradient from $100 \%$ A to $100 \%$ B over $35 \mathrm{~min}$ at a flow rate of $25 \mathrm{ml} / \mathrm{min}$.

\section{Synthesis of citrate-coated gold nanoparticles}

Briefly, $5 \mathrm{ml}$ of $60 \mathrm{mM}$ Gold Chloride (Sigma) was added to $470 \mathrm{ml}$ of deionized water and heated to boiling while being stirred. Upon boiling, $25 \mathrm{ml}$ of $18 \mathrm{mM}$ trisodium citrate was added to the solution and the reaction was terminated once a deep red solution color was obtained. The solution was allowed to cool to room temperature and the gold nanoparticles (AuNP) separated by centrifugation $(15,000 \mathrm{rpm}, 5 \mathrm{~min})$. They were stored room temperature.

\section{PEG-6000 coated gold nanoparticles}

$1 \mathrm{~g}$ of methyl-PEG-6000 was added to a $10 \mathrm{ml}$ solution of citrate-capped Au nanoparticles $(50 \mathrm{mg}$ ) and stirred for $1 \mathrm{~h}$ allowing citrate to exchange with mPEG-6000, resulting in non-covalent attachment of PEG to the Au nanoparticles. Excess mPEG-6000 was removed by centrifugation at $15,000 \mathrm{rpm}$ for $30 \mathrm{~min}$ and discarding the supernatant. The pellet was re-suspended in $1 \mathrm{M} \mathrm{HEPES}$ and stored in $4{ }^{\circ} \mathrm{C}$.

\section{Determination of loading efficiency of PDC on PEG AuNPs}

A $4 \mathrm{mM}(3.9 \mathrm{mg})$ solution of each PDC was added to a1 ml PEG-Au NP solution and the mixture stirred for $30 \mathrm{~min}$ at room temperature. PDC loading efficiency was determined by centrifuging the mixture at $15,000 \mathrm{rpm}$ for $5 \mathrm{~min}$ and determining the concentration of free PDC in the supernatant by LC/MS. No traces of PDC were found in the supernatant.

\section{Characterization of the PDC-PEG-AuNPs Electrophoretic mobility assay}

To obtain a qualitative measurement of PDC attachment to the NPs, gel electrophoresis of naked, PEG-coated and PDC-PEG-coated AuNPs was performed in a $1.5 \%$ agarose gel in TAE running buffer. The field strength was held constant at $120 \mathrm{~V}$ and the current was $97 \mathrm{~mA} .50 \mu \mathrm{l}$ of AuNP solutions were mixed with $50 \mu \mathrm{l}$ of 1:9 glycerol/ buffer solution and loaded onto the gel.

\section{Morphology}

The surface plasmon characteristics of the AuNP before and after coating were analyzed using a Varion Cary 50 Bio UV-VIS spectrophotometer. The morphology of the nanoparticle was determined by transmission electron microscopy (TEM). The nanoparticles were negatively 
stained with $2 \%$ phosphotungstic acid and placed on a carbon-coated copper grid. The particles were then examined with a JOEL JEM 1400 transmission electron microscope operating under an accelerating voltage of $80 \mathrm{kV}$. The micrographs of the nanoparticles were obtained using Olympus Keen view CCD camera attached to the microscope. FTIR analysis (Bruker Vertex 70) was used to characterize the chemical binding of both PEG and peptide drug conjugate to the surface of the nanoparticle.

\section{Stability of PDCs and PDC-coated PEG-Gold nanoparticles}

Stock solutions were prepared by dissolving $5 \mathrm{mg}$ of P4-chlorambucil, P4-melphalan or P4-bendamustine coated PEG-AuNPs in $1 \mathrm{~mL}$ of deionized water.

\section{Chemostability}

$100 \mu \mathrm{l}$ of stock solution were diluted to $1 \mathrm{ml}$ of $0.01 \mathrm{M}$ phosphate buffer solution $\mathrm{pH} 7.2$ and incubated at $37^{\circ} \mathrm{C}$. At designated time points an aliquot was removed and centrifuged at $5000 \mathrm{rpm}$ for $5 \mathrm{~min}$. The supernatant was recovered, filtered through a $0.22 \mu \mathrm{M}$ syringe and analyzed by LCMS for the presence of free drug. Results for each time point were expressed as mean $\%$ PDC integrity \pm standard error, calculated from two independent experiments.

\section{Biostability in liver homogenate}

Mice were sacrificed by $\mathrm{CO}_{2}$ euthanasia. Livers were removed, and rinsed in cold $0.01 \mathrm{M}$ PBS buffer $\mathrm{pH}$ 7.4. They were transferred to $10 \mathrm{ml}$ Tris-HCI, pH 7.4 and homogenized in in a Potter-Elvehjem glass tissue grinder for $4 \mathrm{~min}$. The tissue homogenate was centrifuged for $20 \min$ at $4{ }^{\circ} \mathrm{C}$, $14,000 \mathrm{rpm}$, and the supernatant was collected. Protein concentration was measured using the BCA protein assay using bovine serum albumin as a standard. The homogenate was used immediately or else stored in liquid nitrogen.

$100 \mu \mathrm{l}$ of each sample was added to $1 \mathrm{ml}$ of liver homogenate (equivalent to $6 \mathrm{mg}$ total protein). The samples were incubated at $37{ }^{\circ} \mathrm{C}$ and aliquots were taken during the different incubation period at different time intervals. The collected aliquots were immediately filtered, and analyzed by LC-MS.

\section{Cell cytotoxicity assay}

To measure drug cytotoxic effect, cells were seeded into 96-wells Nunclon culture plates at $2.5 \times 10^{3}$ cells per well and grown overnight at $37{ }^{\circ} \mathrm{C}$. The spent medium was removed and the cells cultured for $72 \mathrm{~h}$ in fresh medium containing either free drug, PDCs, PEG-AuNPs or PDCPEG-AuNPs at concentrations ranging from 0 to $50 \mu \mathrm{M}$ (drug) filtered through a $0.22 \mu \mathrm{m}$ syringe. Cellular metabolic status, used as a measure of cell viability, was then determined by replacing the culture medium with fresh medium containing XTT reagent $(50 \mu \mathrm{l} /$ well $)$ and the cells were re-cultured for $2 \mathrm{~h}$ sat $37^{\circ} \mathrm{C}$. Absorbance in the wells was measured at $450 \mathrm{~nm}$ and subtracted from the reference absorbance at $630 \mathrm{~nm}$. Culture medium was used as background control. All experiments were performed in triplicate on three separate occasions. Data are presented as mean \pm S.D.

To further test the effect of nanoparticles conjugation on PDC activity, free drugs, PDCs and PDC-PEG-AuNPs were pre-incubated in growth medium for 24,48 or $72 \mathrm{~h}$ at $37{ }^{\circ} \mathrm{C}$ after which time the solutions were added to fresh A20 cells. The cells were grown for a further $72 \mathrm{~h}$ and cytotoxicity was determined.

\section{Statistical analyses}

Stability and cellular metabolism assays were performed in triplicate. Final results were calculated as the mean \pm standard deviation of repeat experiments. Differences between groups were evaluated for statistical significance using the one-tailed $t$ test for groups with equal variance. A $\mathrm{p}$ value of $\leq 0.05$ was taken as statistically significant.

\section{Results \\ Identification of phage peptides specifically internalized by $A 20$ cells}

Before exposure to the target cells, the stock Ph.D-7 linear phage display library was sequentially absorbed in vitro on a series of normal human and mouse cells and on Matrigel, in an effort to remove as many phage clones as possible that display peptides against normal cell surface and matrix polymer components. As shown in Additional file 1: Figure S2, this process reduced the stock concentration from $\sim 3 \times 10^{10} \mathrm{pfu} / \mu \mathrm{l}$ to $\sim 10^{6} \mathrm{pfu} / \mu \mathrm{l}$. This absorbed library was then amplified to expand the number of each of the remaining clones and to restore the initial phage concentration.

The absorbed library was then exposed to A20 cells. Unbound phage were removed and cell bound phage eluted. The cells were then lysed and internalized phage recovered and amplified. These phage were similarly subjected to two more exposure cycles on fresh A20 cells. Internalized phage from cycle 3 were titrated on bacterial lawns and 15 isolated plaques were randomly selected and designated P1, P2, P3...P15. ssDNA was extracted separately from each phage colony, the DNA sequences of the PIII displayed peptides from each colony obtained by Sanger sequencing and their corresponding peptide sequences derived. Table 1 shows the amino acid sequences of these peptides. Several colonies displayed the same peptide sequence indicating they were derived from the same clones as would be expected after three rounds of selection. From these results three clones, P-4, P- 6 and P-8 were chosen for further study. Initial biochemical analysis of these sequences (http://protcalc.sourceforge. 
Table 1 Peptide sequences of phage internalized by A20 cells and the frequency amongst the sequenced clones

\begin{tabular}{lll}
\hline Clone designation & Peptide sequence & Number of repeats \\
\hline P-1 & IEE GLY GLY ASN LEU SER ALA & 1 \\
P-2 & GLY VAL ALA IIE THR MET LYS & 2 \\
P-4 & HIS SER THR PRO SER SER & 7 \\
& PRO & \\
P-6 & ASN ASP LEU MET ASN ARG & 2 \\
& ALA & \\
P-8 & ASP SER SER LEU PHE ALA & 3 \\
& LEU & \\
&
\end{tabular}

net/cgi-bin/protcalc) indicated that at physiological $\mathrm{pH}, \mathrm{P} 4$ would be essentially not charged, while P6 and P8 would be negatively charged ( -2.2 and -1.2 respectively).

These three peptides were synthesized with or without FITC conjugated to their $\mathrm{N}$-termini. Their binding to target A20 cells was determined by flow cytometry (Fig. 1). The binding of each peptide was dose-dependent, however P4 and P8 bound by almost twice as much as did P6 at most of the concentrations tested. The conjugates were also tested with confocal microscopy to compare peptide internalization into A20 cells as shown in Fig. 2. Clearly, P4 and P8 are taken up by the cells. Surprisingly

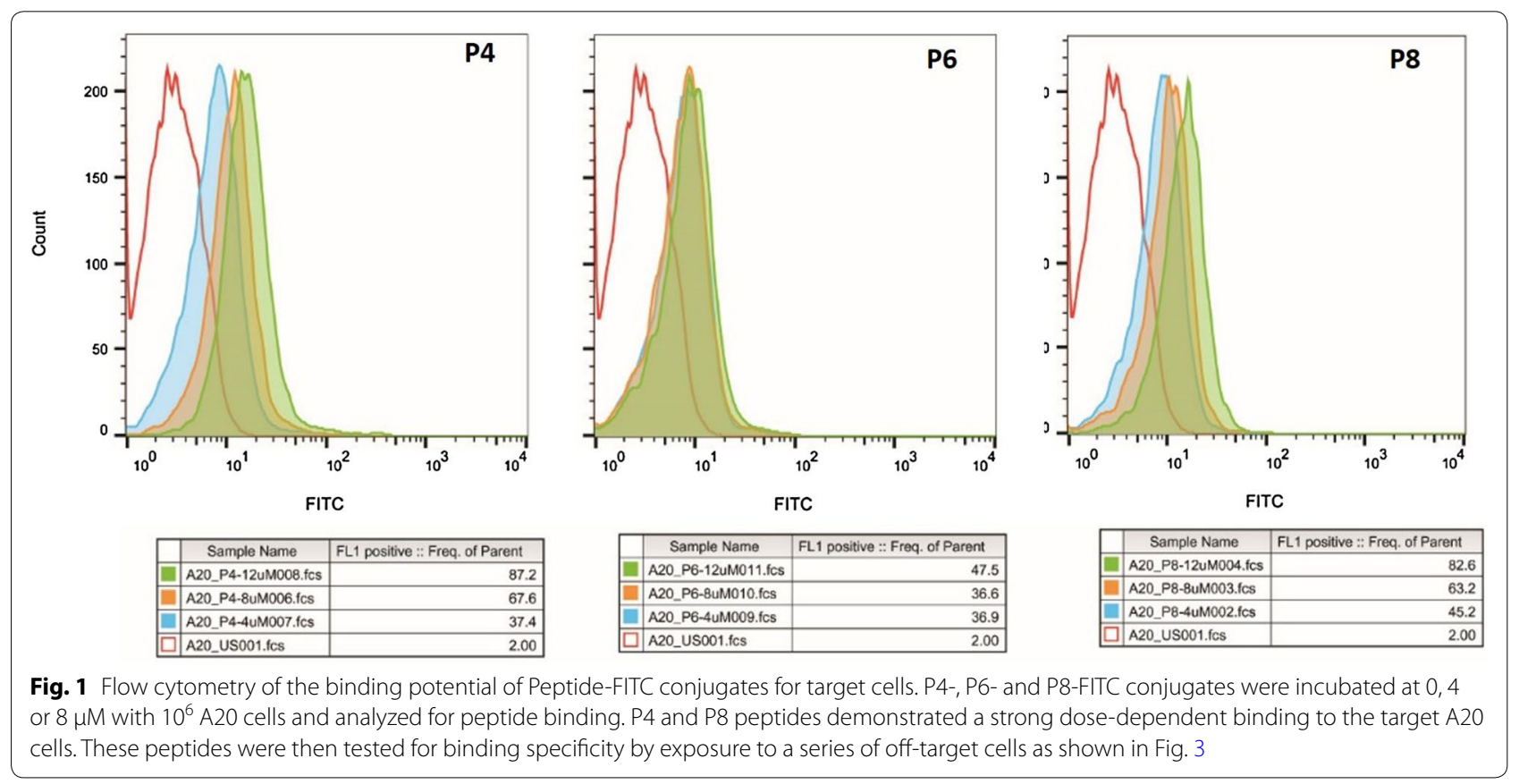

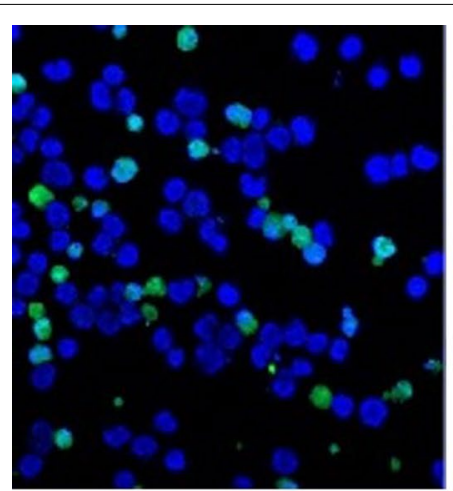

P4-FITC

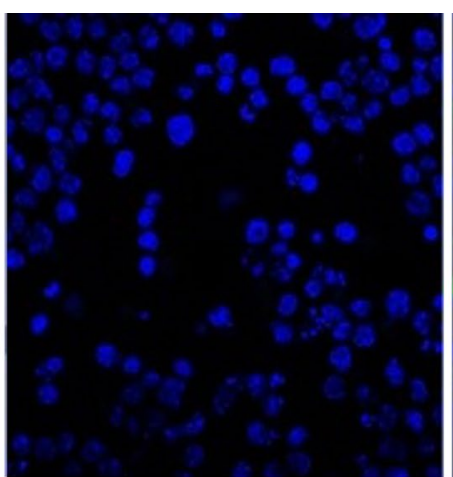

P6-FITC

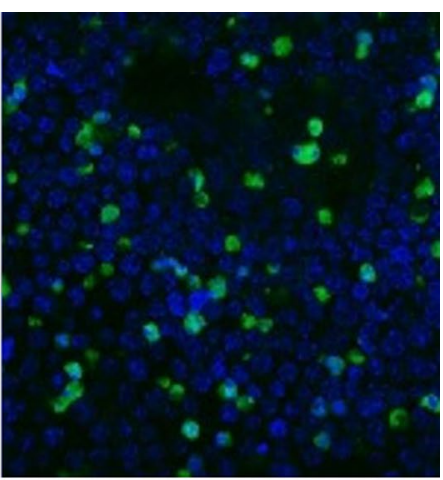

P8-FITC

Fig. 2 Ability of peptides to internalize into A20 cells. P4, P6 and P8-FITC conjugates were incubated with A20 cells. After several washes and counterstaining with DAPI, the cells were viewed by confocal microscopy. The P6 conjugate did not penetrate into the cells unlike P4 and P8. The FITC marker localization is extra-nuclear 
P6, which also bound to A20 (Fig. 1) did not internalize into the cells.

\section{Specificity of peptides for target and off-target cells}

Based on the results above and the peptide copy numbers from Table 1, we chose to further investigate the activity of P4as a positive binder and P6 as a negative/weak binder. P4-FITCand P6-FITC were tested by flow cytometry for their binding at several concentrations to a panel of off-target lymphoid and myeloid cells, as illustrated in Fig. 3. At $8 \mu \mathrm{M}$, neither peptide bound to either human
PBMCs or to MOPC 315.BM leukemic cells. P4 bound to a small population of NB4 cells (human acute myeloid leukemia) (10.3\%) and HL-60 cells (human acute promyelocytic leukemia) (13.8\%), while P6 was negative for NB4 and bound only $6.9 \%$ of HL-60 cells. These results suggest that P4 may bind a cell surface component shared with a small sub-population of human myeloid leukemic cells.

\section{Cytotoxicity of free and peptide conjugated drugs}

Cells were seeded overnight on microplate culture wells, washed, and re-cultured with fresh medium containing

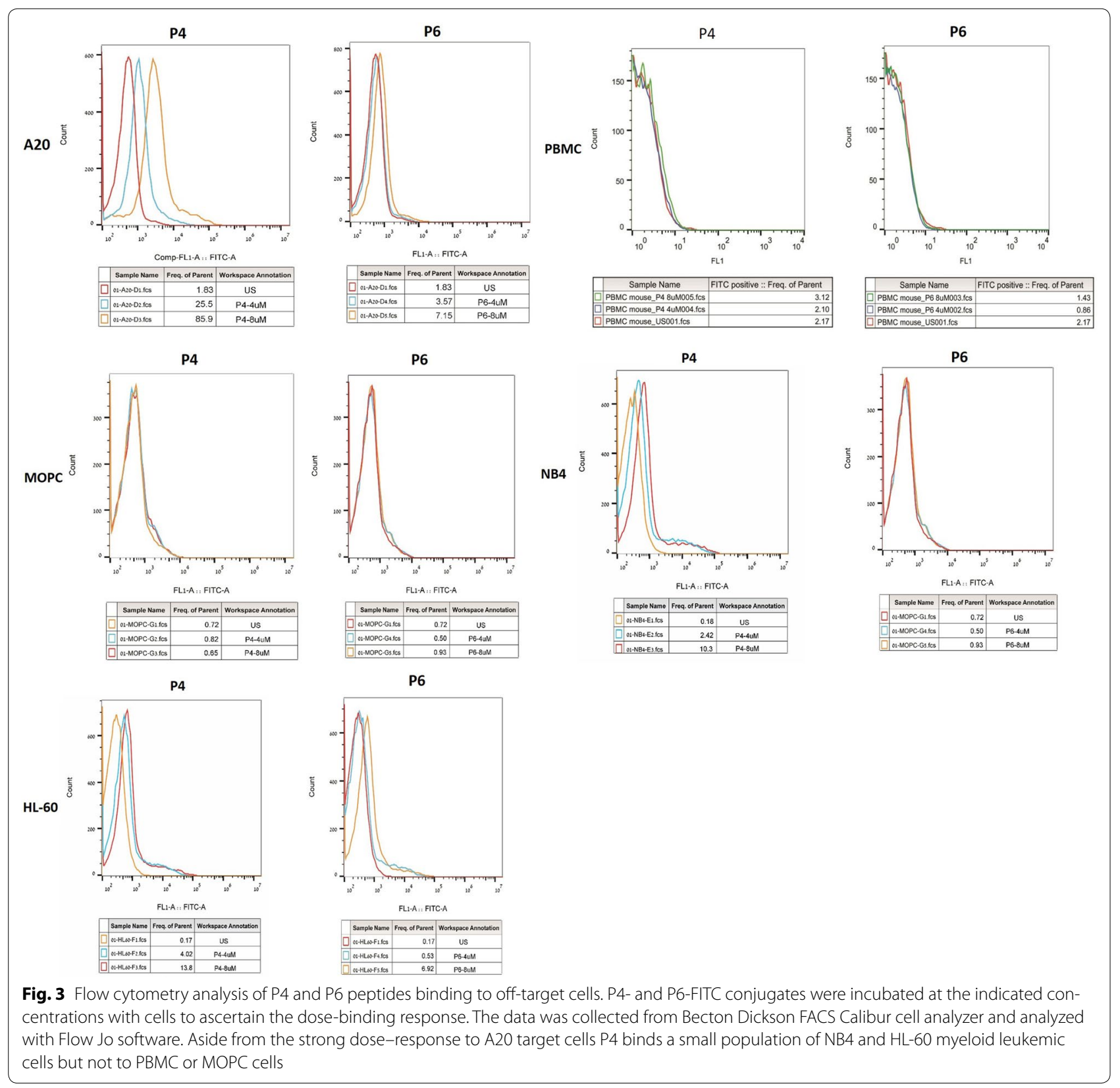


increasing doses $(0-50 \mu \mathrm{M})$ of free chlorambucil, melphalan or bendamustine or P4- or P6-conjugates of these drugs. After a further $72 \mathrm{~h}$ culture, the cytotoxicity of the compounds was determined by measuring cellular metabolism (Fig. 4). The results were expressed as $\%$ Growth Inhibition compared to cells not exposed to drug. Clearly A20 cells are significantly more sensitive to Chlorambucil and Melphalan than they are to bendamustine $\left(\mathrm{IC}_{50}\right.$ values $15.8,9.6,>50 \mu \mathrm{M}$ respectively; maximal $\%$ GI 89.4, 94.9 and 43.1 respectively). Conjugation of the drugs to P4 affected their efficacy toward A20 cells. For chlorambucil and melphalan, conjugation reduced the cytotoxic effect and this was significant for chlorambucil at $25 \mu \mathrm{M}(\mathrm{p}=0.0013)$. On the other hand, conjugation significantly improved the cytotoxic effect of bendamustine at $25(\mathrm{p}=0.043)$ and $50 \mu \mathrm{M}(\mathrm{p}=0.048)$. The efficacies of all P6-conjugates were significantly lower than those of P4-conjugates at concentrations above $10 \mu \mathrm{M}$.
The spectrum of cytotoxicity of free and P4-conjugated drugs was also tested against three off-target myeloid and lymphoid cell lines. As shown in Additional file 1: Figure S3, the free drugs were equally cytotoxic to all three cell lines. However all the P4-PDCs showed very low activity against these cells, reflecting the FACS binding results in Fig. 3. These results for P4-PDCs in Fig. 4 as well as the P6-PDCs in Additional file 1: Figure S3 show that the conjugates essentially reached a plateau of activity at about $10 \mu \mathrm{M}$ (drug), demonstrating that delivery of even a $5 \times$ excess PDC does not lead to increased uptake of conjugate by off-target cells.

\section{Stability of P4-drug PDCs}

The chemo-stability of the P4-PDCs was tested at a physiological $\mathrm{pH}$ of 7.4, while the solutions were incubated at $37^{\circ} \mathrm{C}$. Biostability was assessed after incubation in a mouse liver homogenate. In each case aliquots were
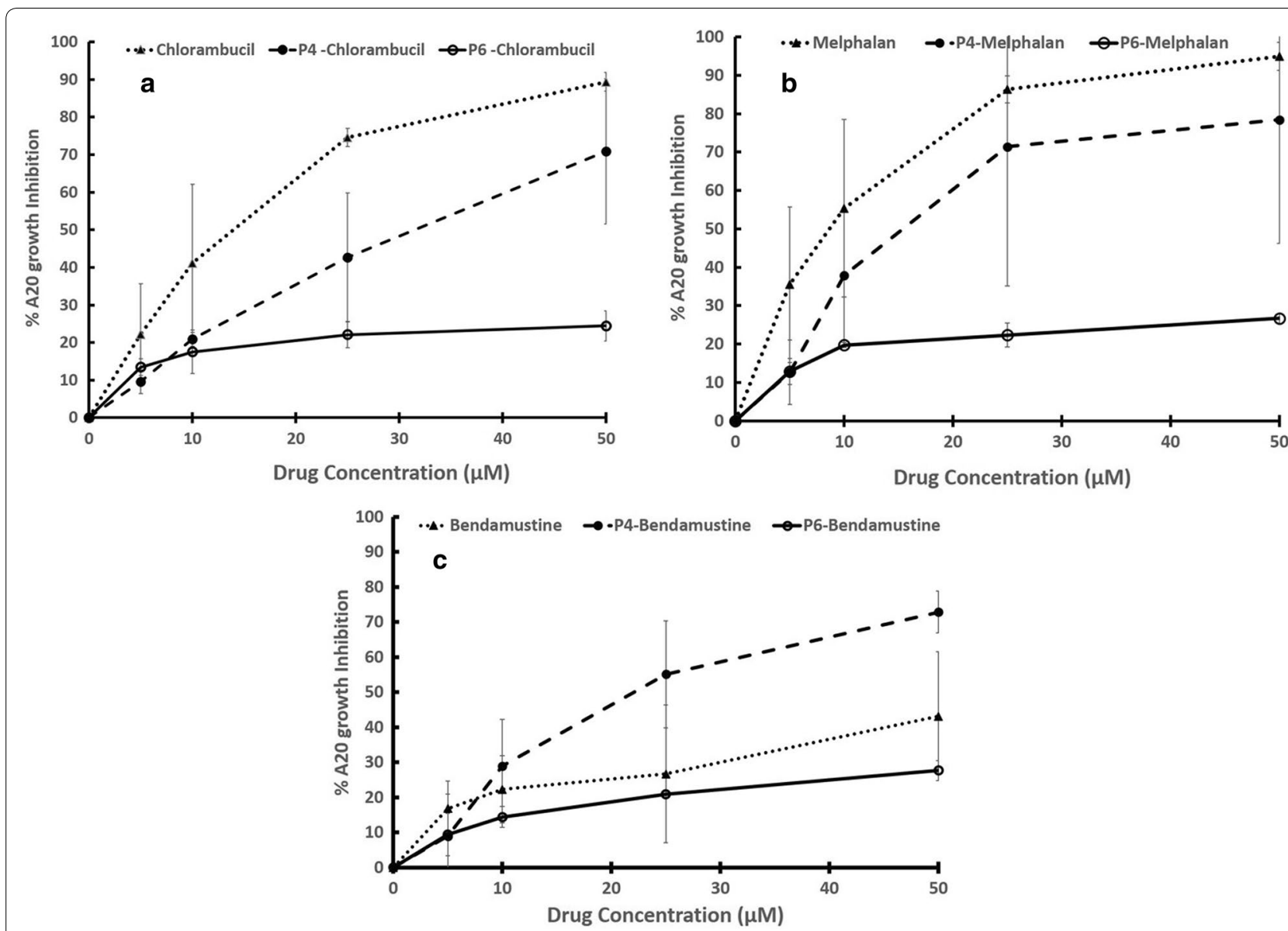

Fig. 4 Cell growth Inhibition assay by free and conjugated drugs. Growth inhibiting effect of drug-conjugates VS free drugs was studied on a chlorambucil, $\mathbf{b}$ melphalan, $\mathbf{c}$ bendamustine. At the end of $72 \mathrm{~h}$ incubation period cell growth was assessed using the XTT assay: optical density (OD) was measured at 480 and $680 \mathrm{~nm}$ - the latter is the background absorbance. The difference between the 480 and $680 \mathrm{~nm}$ measurement was used to calculate the \% growth inhibition (Gl) in test wells compared with control cells exposed to medium alone. The results shown for each concentration point represent the mean \pm standard error for two independent experiments each conducted in $(n=3)$ 


\section{Chemostability, pH 7.4}
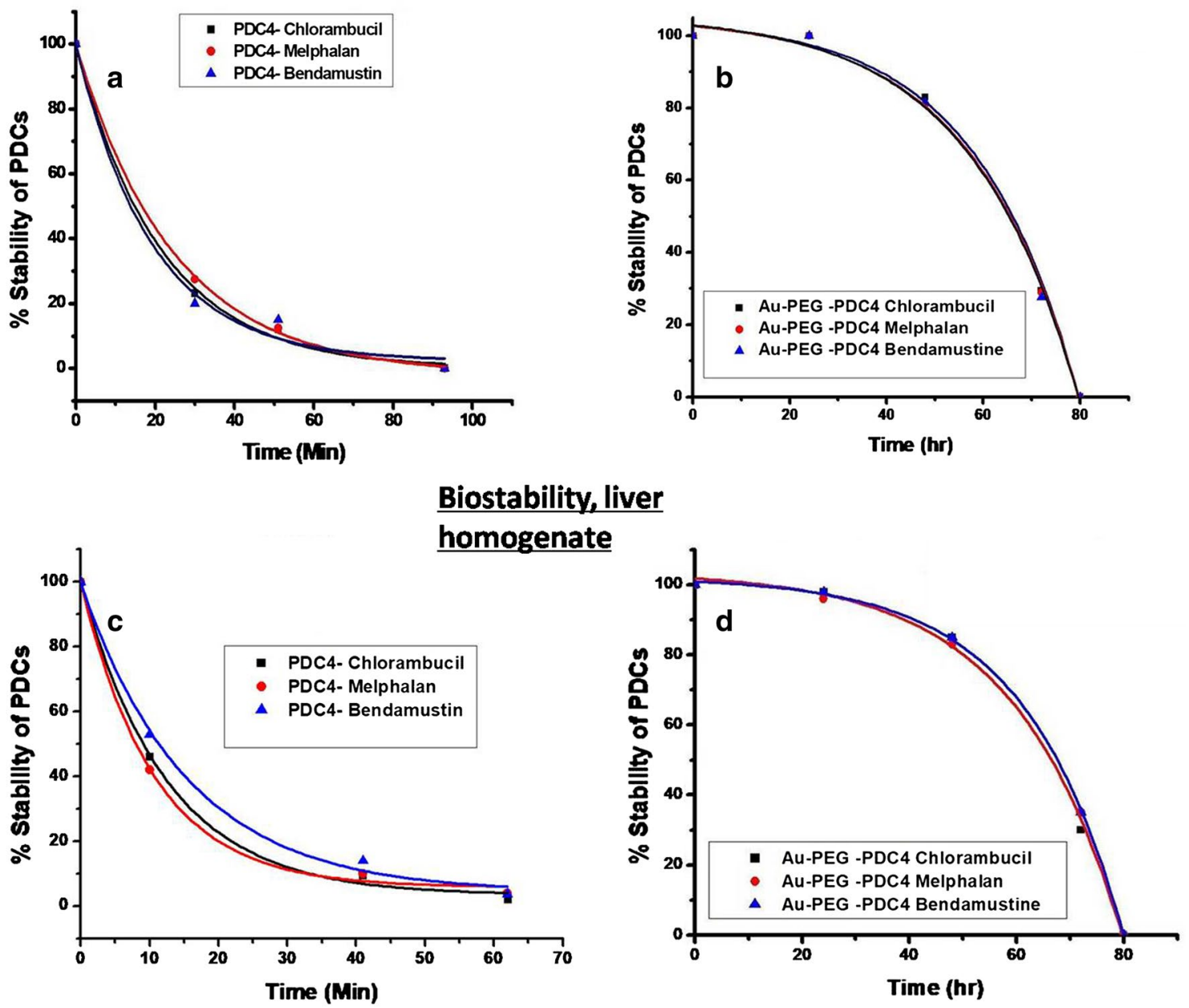

Fig. 5 Stability of free PDCs and PDC-PEG-AuNPs. Chemostability was assessed by incubation the constructs in $0.01 \mathrm{M}$ phosphate buffer solution $\mathrm{pH} 7.2$ at $37^{\circ} \mathrm{C}$ for different time intervals. Biostability was assessed by incubation in a mouse liver homogenate at $37^{\circ} \mathrm{C}$. At the indicated time intervals, aliquots were taken, filtered or centrifuged (respectively) and analyzed by LC-MS for PDC integrity. Graphs a and c represent results for PDCs while graphs $\mathbf{b}$ and $\mathbf{d}$ represents results for Au-PEG-PDCs. Results are expressed as mean \% PDC integrity \pm standard error, calculated from two independent experiments

taken at selected times and analyzed by LC-MS. PDC integrity was determined by calculating the area under the curve of the PDC peak. The $\mathrm{R}^{2}$ values of the exponential decay curves ranged from 0.97 to 0.99 for the three PDCs; the functions of these curves were used to calculate the $t^{1 / 2}$ values. The results (Fig. 5a) showed that after 30 min incubation in buffer, $80 \%$ of PDCs had decomposed and they had completely broken down by $1.5 \mathrm{~h}$. The $t^{1} / 2$ values ranged from 19.3 to 24.6 min (Additional file 1: Table S1 I). In liver homogenate (Fig. 5c), stability decayed more rapidly with half-lives ranging from 10.6 to $15.4 \mathrm{~min}$. There was no significant difference in behavior between the three PDCs and no free drug was observed.
Based on these results, we sought to improve the stability of the PDCs by conjugated them to gold nanoparticles. The physico-chemical parameters of the constructs were characterized and then their biological activity was tested.

\section{Characterization of PDC-coated PEG-AuNPs Electrophoresis mobility assay}

Electrophoretic migration is dependent on the charge and size of dispersed colloidal particles and was used here as a measure of nanoparticle positive charge as a result of peptide co-functionalization. As uncoated AuNPs easily aggregate in TAE electrophoresis buffer, coating with PEG-6000 should allow their dispersion and mobility 
within the gel, as was indeed the case (Additional file 1: Figure S4, Lane 1). Coating the PEG-AuNPs with PDCs retarded this mobility, indicating a reduction in the overall negative charge of the nanoparticles to slightly different degrees depending on the electrochemistry of both the amino acid sequence and the drug.

\section{Size and morphology of the PDC-PEG coated-Au nanoparticles}

Coated gold nanoparticles were obtained through a non-covalent coating process. UV-VIS spectra analyses showed no significant change in the $530 \mathrm{~nm}$ surface plasmon band peak of the AuNPs as a result of coating them with PEG and PDC (Additional file 1: Figure S5), indicating that conjugation did not significantly change the size of the particles or aggregate them. Additional file 1: Figure S6 depicts the DLS data for these particles.

Morphology was determined by TEM are shown in Fig. 6. The nanoparticles were spherical in shape with a smooth surface (a and d). After coating them with PEG a characteristic "PEG corona" can be seen (b and e) as has been reported by others [22-24]. There was no significant difference in this morphology when the PEG-AuNPs were coated with PDCs containing P4 and Chlorambucil (c and $\mathrm{f}$ ), melphalan or bendamustine (data not shown).
Dynamic light scattering measurements showed a particle size distribution of $25-40 \mathrm{~nm}$ (data not shown).

\section{FTIR analyses of coated nanoparticles}

The nanoparticle conjugates were characterized by FTIR to confirm the chemical binding of both PEG and PDC binding to the surface of the gold nanoparticle. The results are shown in Fig. 7. Both naked and PEGcoated AuNPs displayed signals at 950, 1092, 1646 and $3304 \mathrm{~cm}^{-1}$. The presence of hydroxyl groups utilized to link PEG to the oxide surface (Fig. 7a) was confirmed by the absorbance peak for $\mathrm{O}-\mathrm{H}$ stretch at $1092 \mathrm{~cm}^{-1}$ on all nanoparticle spectra. Previous studies showed that nanoparticles functionalized with PEG- $\mathrm{NH}_{2}$ display a series of IR absorbance peaks in the range $3300-700 \mathrm{~cm}^{-1}$ corresponding to the stretching and bending of several types of chemical bonds [25-28]. PEG-AuNPs coated with P4 PDCs (Fig. 7b) showed additional absorption peaks at, 1425, 1313.3, 1018 and $946 \mathrm{~cm}^{-1}$ providing evidence of PDC attachment to the PEG-AuNP.

\section{Stability of PDC coated PEG-AuNPs}

The stability of the PDC-PEG-AuNPs is a key factor for the potential use of AuNPs in targeted drug delivery systems. Initial investigation of its stability in buffer solution
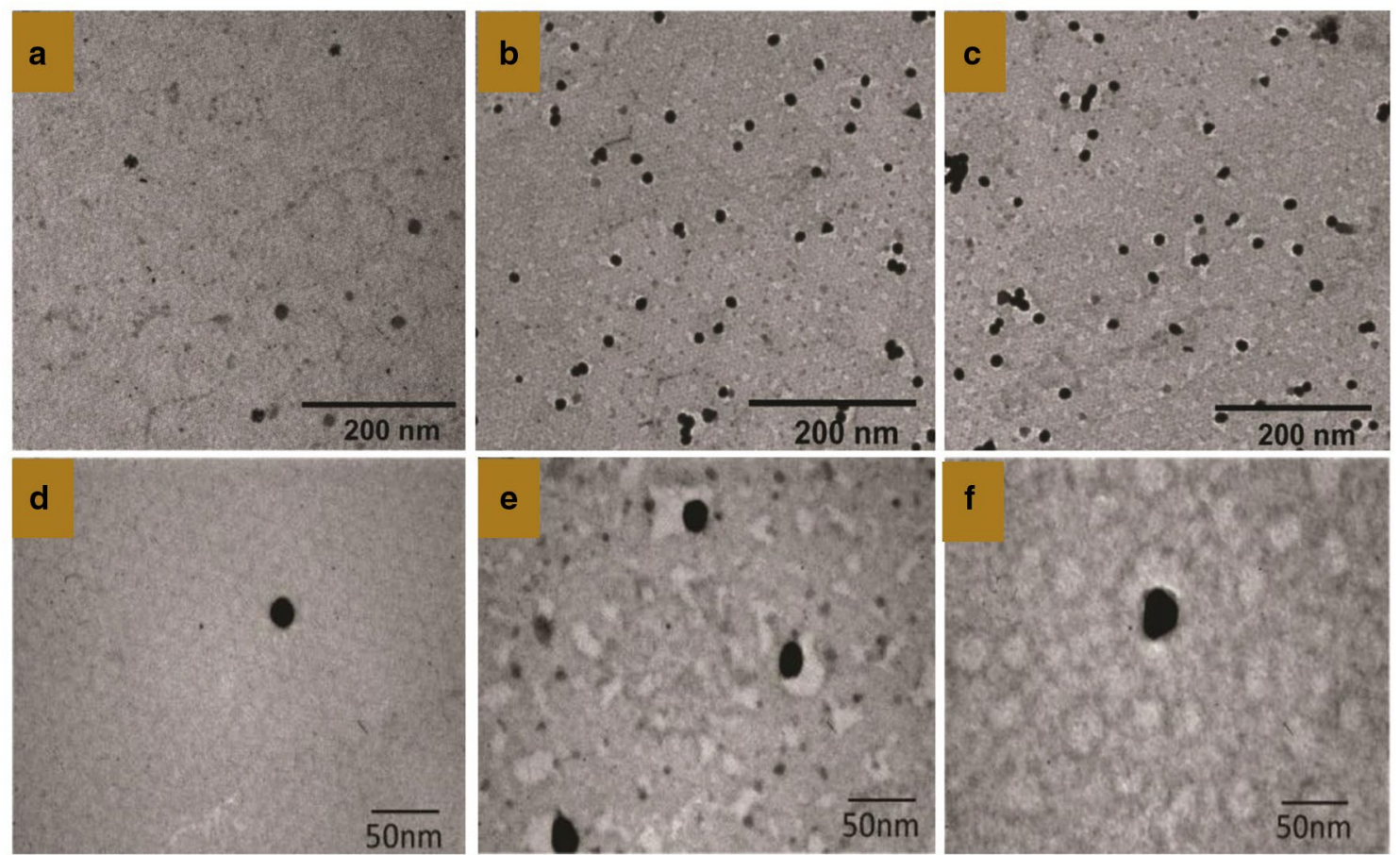

Fig. 6 TEM images of PEG-coated gold nanoparticles. Samples were negative stained with 1\% phosphotungstic acid; thereafter, images were taken. Scale bars $=200,20 \mathrm{~nm}$. a, d Naked Gold nanoparticles (negative stained with 1\% phosphotungstic acid; there is no white coated around the nanoparticles (uncoated PEG6000). b, e Gold nanoparticles coated PEG-6000 (negative stained with 1\% phosphotungstic acid) black color gold nanoparticles - white color PEG6000 (negative stain). c, f Gold nanoparticles coated PEG-6000 + PDC4 - chlorambucil (negative stained with 1\% phosphotungstic acid) 

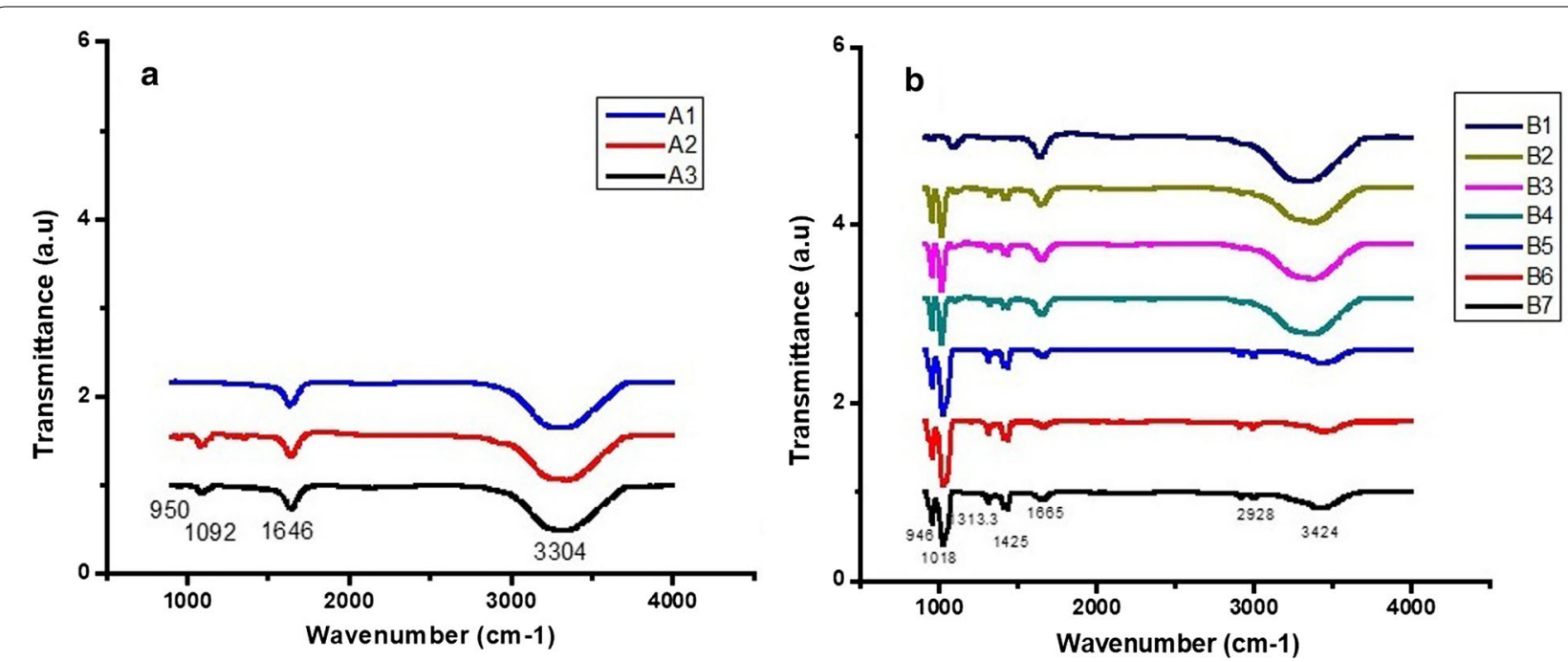

Fig. 7 Fourier Transformed Infra-Red spectra of PEG and PDC binding to gold nanoparticles. FTIR analysis was used to characterize the chemical binding of both PEG and Peptide drug conjugate to the surface of the nanoparticle. For the chemical bond significant of each peak, please refer to the text. a A1 - gold nanoparticles; A2_PEG 6000; A3_PEG-6000 coated gold nanoparticles. b B1_PEG-6000 coated gold nanoparticles; B2gold nanoparticles coated peptide4_chlorambucil; B3_PEG-6000 coated gold nanoparticles_PDC peptide4—-melphalan; B4_PEG-6000 coated gold nanoparticles_PDC peptide4-Bendamustine; B5_PDC peptide4—chlorambucil; B6_PDC peptide4- melphalan; B7—PDC peptide4bendamustine

at physiological pH 7.4 was carried out. Aliquots were taken at various time points, and the concentrations of released drug were determined by quantitative LC-MS analyses. Figure $5 \mathrm{~b}$ shows that the PDCs were completely stable over the first $24 \mathrm{~h}$ in contrast to the limited stability of PDCs alone (Fig. 5a). After $48 \mathrm{~h}$ stability had been reduced by $17 \%$ and by $100 \%$ after $80 \mathrm{~h}$. The $\mathrm{t}^{1 / 2}$ values ranged from 21.0 to $22.3 \mathrm{~h}$. There was no significant difference in behavior between the three PDC conjugates.

\section{Cytotoxicity of PDC-coated PEG-AuNPs}

We then tested whether the enhanced stability of the AuNP conjugated P4-PDC could be garnered to extend the cytotoxic activity of the P4-PDC. Free drugs, free PDC4 and P4-PDC-PEG-AuNPs were pre-incubated in culture medium for 24,48 or $72 \mathrm{~h}$ at $37^{\circ} \mathrm{C}$ and then added to fresh A20 cells for a further $72 \mathrm{~h}$. Figure 8 shows the results, corrected for cytotoxicity induced by gold particles alone (5-12\% from lowest to highest concentration). All three P4-PDC-coated gold nanoparticles pre-incubated for 24 or $48 \mathrm{~h}$ induced statistically similar cytotoxicity in A20 to that induced by freshly prepared PDC4 and to coated particles without pre-incubation (the latter data not shown). After $72 \mathrm{~h}$ pre-incubation, cytotoxic activity of all three P4-PDC was significantly lower than fresh P4-PDC at the highest concentration $(\mathrm{p}<0.01)$. In contrast, pre-incubation of free drug or free P4-PDC, even for $24 \mathrm{~h}$ reduced their cytotoxic effect by $>93 \%$ (data not shown). The target cell specificity of the
P4-PDC-coated nanoparticles did not react against several off-target cells (Additional file 1: Figure S9).

\section{Discussion}

One of the main goals of targeted drug delivery systems is to reduce unwanted toxicities by delivering the therapeutic war-head specifically to pathologic cells, thereby reducing the exposure of healthy cells to the drug. In this regard phage display peptide technology is a powerful tool for the discovery of novel peptides that can be used to target cytotoxic drugs to cancer cells [29]. The flexible use of these peptides to generate mono- and dual drug peptide-drug-conjugates $[7,8,21]$ is offering new possibilities to develop more effective cancer therapies [30].

Nonetheless, the stock phage pool contains many clones with low affinity for candidate target receptors. These clones might lead to a cross-reactive or non-specific binding overload that successfully competes with less abundant, but higher affinity clones. Therefore prior to exposing the stock phage library to our A20 target leukemic cells, we removed from the library clones with affinity for cell surface components present on several types of off-target cells. We surmised that this strategy might increase the possibility of fishing out clones that bind unique receptor(s) on the A20 target cells. Indeed the procedure significantly reduced the library size almost 5 order of magnitude (Additional file 1: Figure S2).

Initially, the goal of our study was to monitor the pharmacokinetics and anti-cancer efficacy of novel lymphoma 

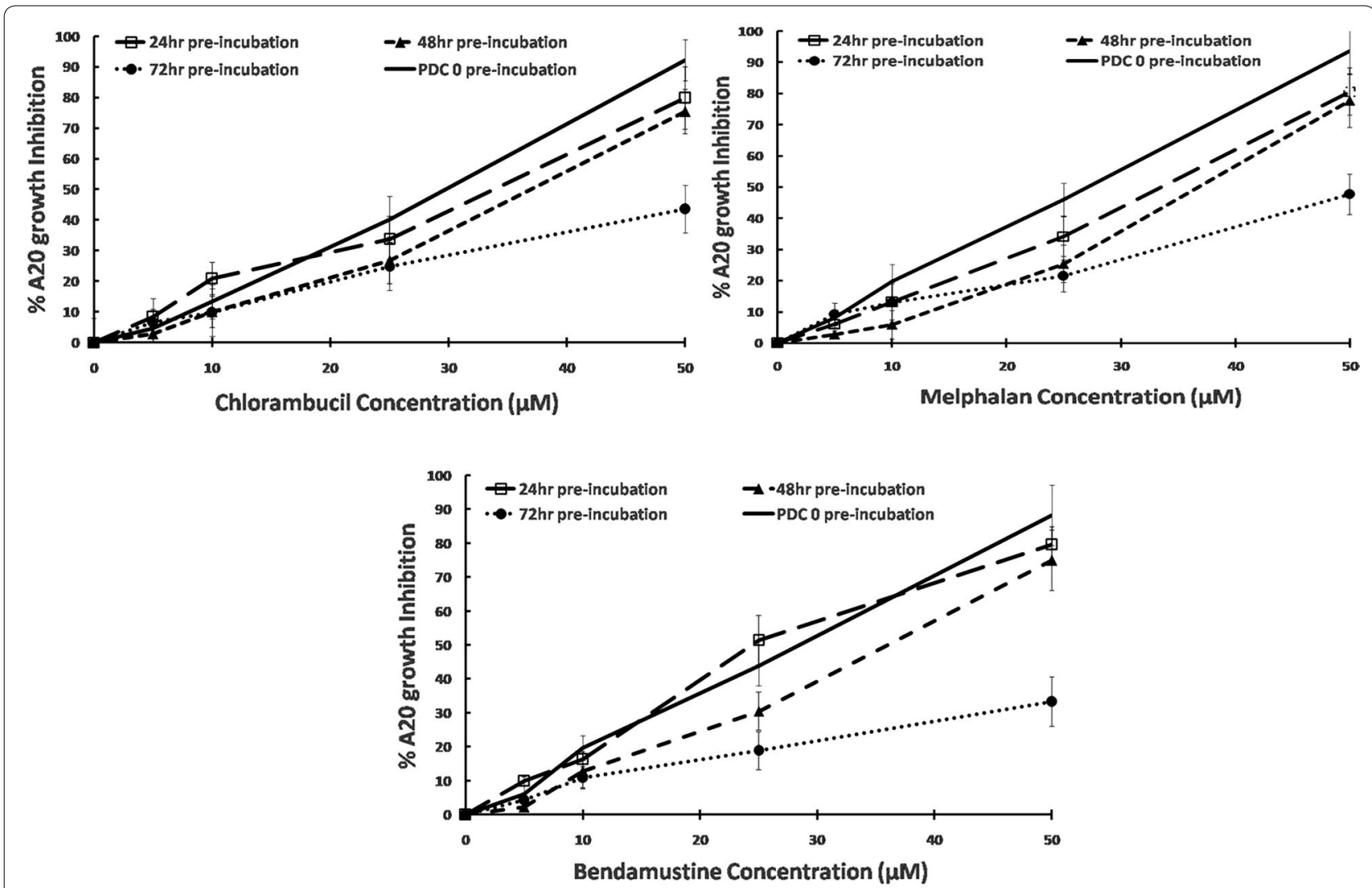

Fig. 8 Effect of drug or P4-PDC pre-incubation of cytotoxic activity. Free drugs, free P4-PDCs or P4-PDC-PEG-AuNPs were incubated for 24,48 or $72 \mathrm{~h}$ at $37^{\circ} \mathrm{C}$ and then added to A20 cells for a further $72 \mathrm{~h}$ after which cell growth was assessed using the XTT assay: optical density (OD) was measured at 480 and $680 \mathrm{~nm}$ - the latter is the background absorbance. The difference between the 480 and $680 \mathrm{~nm}$ measurement was used to calculate the \% growth inhibition (Gl) in test wells compared with control cells exposed to medium alone. The results shown for each concentration point represent the mean \pm standard error for two independent experiments each conducted in $(n=3)$. Only the results for fresh P4-PDC versus pre-incubated P4-PDC-PEG-AuNPs are shown as pre-incubation of free drugs or free PDC4 abolished their cytotoxic activity by more than $93 \%$

PDCs using the A20 cell line as a model. Using the "absorbed phage library", we discovered several clones internalized by the target cells (Table 1). We chose to study P4, P6 and P8. The P4 clone was repeated a number of times amongst those clones sequenced and may have higher affinity for a receptor. P2 was overlooked because its predicted net positive charge of 0.8 at $\mathrm{pH} 7.4$ (data not shown) may lead to non-specific electrostatic binding to cell surface components. On the other hand P6 and P8 are predicted to have negative charges at $\mathrm{pH} 7.4(-2.2$ and -1.2 respectively) due to the presence of carboxylate moiety of aspartic acid. P4, P6 and P8 were synthesized and shown to bind the target cells (Fig. 1), but only P4 and P8 actually internalized into the cells in their free form (Fig. 2). This result underscores the importance of verifying that a displayed candidate peptide behaves similarly in the free form to that displayed as an appendage to an exposed phage protein.

The suitability of $\mathrm{P} 4$ as a candidate drug carrier for our model was strengthened by flow cytometry studies showing that while A20 is of B-cell origin, the peptide did not bind to either to a murine myeloma $\mathrm{B}$ cell line or to normal human lymphocytes (Fig. 3). It did however appear to bind a small population of human myeloid derived leukemic cells. We tested the cytotoxic efficacy of three chemotherapeutics in their free form and after conjugation to P4. Figure 4 shows that A20 cells were less sensitive to bendamustine than to chlorambucil or melphalan. Arimany-Nardi et al. [31] recently reported that Bendamustine enters the cell through the hOCT1 transporter which is expressed on some lymphoma cells [32] although the protein's expression on A20 cells is not known. In contrast, early studies showed that Chlorambucil is taken up by simple diffusion [33,34], however it too is not taken up by all leukemic cells $[4,6]$. Melphalan is actively taken up by L-type amino acid transporter 1 (LAT1) which is over-expressed in many types of cancer cells $[35,36]$.

Incorporation of the drugs into PDCs reduced the dose-response effect of Chlorambucil and Melphalan but 
significantly improved the effect of Bendamustine. These variations are to be expected given that PDC incorporation will depend on the receptor cell surface density and the mechanism of internalization. Indeed conjugation to $\mathrm{P} 4$ resulted in their being no significant difference in the dose-response curves of the three PDCs even at the $25 \mu \mathrm{M}$ dose. Interestingly, bendamustine has been reported to be more effective clinically against B-cell leukemias [37, 38], and to possess additional anti-cancer mechanisms of action [39] than chlorambucil. Our results indicate that at least against the A20 leukemic-like cell line the two drugs are equally effective when delivered as PDCs.

PDC stability was assessed in buffer at physiological $\mathrm{pH}$ and after incubation in mouse liver homogenate. In buffer, the $t^{1} / 2$ values ranged from 19.3 to 24.6 min while in liver homogenate they ranged from 10.6 to $15.4 \mathrm{~min}$ (Fig. 5a). By assessing the molecular mass of new LC-MS peaks appearing during the incubation period, we determined that the loss of PDC integrity was mostly due to the hydrolysis of the two chlorines on all three nitrogen mustard drugs, a process which was earlier reported to lead to loss of alkylating activity [40].

To improve the stability of the PDCs, we attached them to PEG-coated gold nanoparticles and characterized the physico-chemical parameters of the resulting conjugates (Additional file 1: Figures S3, S4 and Figs. 6, 7). While many types of nanoparticles have been tested as potential vehicles for targeted cancer drug delivery $[11,13]$, the idea of using gold particles as a mechanism to stabilize PDCs and thus extend their bioavailability has not yet been reported. Indeed this strategy significantly extended the chemical and biological half-lives of the PDCs to 21.0-22.3 h (Fig. 5b). Conjugation to AuNPs also opens up the possibility for developing prolonged targeted cancer cell treatment protocols. We suggest this because pre-incubation of free drugs or free PDCs for $24 \mathrm{~h}$ prior to their exposure to cells reduced their ability to kill A20 targets by $>90 \%$ (data not shown). By contrast, even after $48 \mathrm{~h}$ pre-incubation, the PDC4-PEG-AuNPs retained their cytotoxic capacity (Fig. 8).

Our data suggest a new avenue of application for gold nanoparticles in oncology, including hematological cancers [12], by directly combining them with the potential for targeted cancer therapy of PDCs [21, 30, 41]. The ability of AuNPs to extend the bioavailability of PDCs may circumvent the need for the particles to actually penetrate the tumor, a noted limitation with some nanoparticles [18]. This strategy may lead to slow release, targeted drug delivery systems which might significantly benefit cancer patients undergoing chemotherapy.

\section{Conclusions}

Peptide-drug-conjugates have demonstrated a number of chemical, structural and biological advantages that hold potential for improving the targeted delivery and efficacy of chemotherapeutic drugs. However one limitation to their clinical application is the relatively short half-live of the constructs in biological fluids and tissue. Our results suggest that this hurdle can be overcome by easily conjugating them to pegylated-gold nanoparticles. By significantly extending PDC stability, this conjugation also opens up the possibility of developing slow release formulations of targeted drug delivery systems containing PDCs.

\section{Additional file}

Additional file 1. Additional figures $\$ 1-\$ 9$ and table $\$ 1$.

\section{Abbreviations}

TDD: targeted drug delivery; PDC: peptide drug conjugate; AuNP: gold nanoparticles; PEG: polyethylene glycol; FITC: fluorescein thiocyanate; PBMC: peripheral blood mononuclear cells; LC--MS: liquid chromatography-mass spectroscopy; TAE: Tris-acetic acid-EDTA buffer; FTIR: Fourier transformed infrared spectroscopy.

\section{Authors' contributions}

KK-experimental and manuscript preparation. B-CL_experimental. ABexperimental and manuscript review. GG_chemistry advice and manuscript review. OS-manuscript review. GL-flow cytometry, experimental planning and manuscript review. MF-experimental planning, manuscript preparation and review. All authors read and approved the final manuscript.

\section{Author details}

${ }^{1}$ Dept. Chemical Engineering, Ariel University, 40700 Ariel, Israel. ${ }^{2}$ Eastern R\&D Center, Ariel 40700, Israel. ${ }^{3}$ Dept. Chemical Sciences, Ariel University, 40700 Ariel, Israel. ${ }^{4}$ Tel Aviv \& Pre-Med Faculty, Assuta Medical Center, Institute of Hematology, Ariel University, 40700 Ariel, Israel. ${ }^{5}$ Ariel Center for Applied Cancer Research, Ariel University, 40700 Ariel, Israel.

\section{Acknowledgements}

We gratefully acknowledge assistance by Dr. Pushpa Visvanathan, Head, Electron Microscopy Department, Cancer Institute, Adyar, and Dr. Chennai, India for taking the TEM images.

\section{Competing interests}

The authors declare that they have no competing interests.

\section{Availability of data and materials}

All data generated or analyzed during this study are included in this published article or in Additional file 1.

\section{Consent of publication}

Not applicable.

Ethics approval and consent to participate

Not applicable.

\section{Funding}

This research was funded by the Ariel-Assuta Collaborative Research Fund and the Ariel University Research Authority. KK and B-CL are recipients of Ariel University postdoctoral fellowships. 


\section{Publisher's Note}

Springer Nature remains neutral with regard to jurisdictional claims in published maps and institutional affiliations.

Received: 31 December 2017 Accepted: 21 March 2018

Published online: 30 March 2018

\section{References}

1. Thomas A, Teicher BA, Hassan R. Antibody-drug conjugates for cancer therapy. Lancet Oncol. 2016;17:e254-62.

2. Firer MA, Gellerman G. Targeted drug delivery for cancer therapy: the other side of antibodies. J Hematol Oncol. 2012;5:70.

3. Firer MA, Laptev R, Kasatkin I, Trombka D. Specific destruction of hybridoma cells by antigen-toxin conjugates demonstrate an efficient strategy for targeted drug therapy in leukemias of the B cell lineage. Leuk Lymphoma. 2003;44:681-9.

4. Gellerman G, Baskin S, Galia L, Gilad Y, Firer MA. Drug resistance to chlorambucil in murine $\mathrm{B}$-cell leukemic cells is overcome by its conjugation to a targeting peptide. Anticancer Drugs. 2013;24:112-9.

5. Cohen $\mathrm{S}$, et al. Specific targeting to murine myeloma cells of Cyt1Aa toxin from Bacillus thuringiensis subspecies israelensis. J Biol Chem. 2007:282:28301-8.

6. Gilad Y, et al. 'Switch off/switch on' regulation of drug cytotoxicity by conjugation to a cell targeting peptide. Eur J Med Chem. 2014;85:139-46.

7. Gilad Y, et al. Dual-drug RGD conjugates provide enhanced cytotoxicity to melanoma and non-small lung cancer cells. Biopolymers. 2015. https:// doi.org/10.1002/bip.22800.

8. Gilad Y, et al. Synthesis, biological studies and molecular dynamics of new anticancer RGD-based peptide conjugates for targeted drug delivery. Bioorg Med Chem. 2016:24:294-303.

9. Du AW, Stenzel MH. Drug carriers for the delivery of therapeutic peptides. Biomacromol. 2014;15:1097-114.

10. Pérez-Ortiz M, et al. Gold nanoparticles as an efficient drug delivery system for GLP-1 peptides. Colloids Surf B Biointerfaces. 2017:158:25-32.

11. Wang YF, Liu L, Xue X, Liang XJ. Nanoparticle-based drug delivery systems: what can they really do in vivo? F1000Research. 2017;6:681.

12. Jurj $A$, et al. The new era of nanotechnology, an alternative to change cancer treatment. Drug Des Dev Ther. 2017;11:2871-90.

13. Mendes R, Fernandes A, Baptista P. Gold nanoparticle approach to the selective delivery of gene silencing in cancer - the case for combined delivery. Genes (Basel). 2017:8:94.

14. Ghosh P, Han G, De M, Kim C, Rotello V. Gold nanoparticles in delivery applications. Adv Drug Deliv Rev. 2008;60:1307-15.

15. Rana S, Bajaj A, Mout R, Rotello VM. Monolayer coated gold nanoparticles for delivery applications. Adv Drug Deliv Rev. 2012;64:200-16.

16. De Jong WH, Borm PJA. Drug delivery and nanoparticles: applications and hazards. Int J Nanomed. 2008;3:133-49.

17. Comenge J, et al. Detoxifying antitumoral drugs via nanoconjugation: the case of gold nanoparticles and cisplatin. PLOS ONE. 2012;7:e47562.

18. Wilhelm S, et al. Analysis of nanoparticle delivery to tumours. Nat Rev Mater. 2016;1:16014.

19. Huang $K$, et al. Size-dependent localization and penetration of ultrasmall gold nanoparticles in cancer cells, multicellular spheroids, and tumors in vivo. ACS Nano. 2012;6:4483-93.

20. Xu S, et al. Novel hybrids of natural oridonin-bearing nitrogen mustards as potential anticancer drug candidates. ACS Med Chem Lett. 2014:5:797-802

21. Bashari $\mathrm{O}$, et al. Discovery of peptide drug carrier candidates for targeted multi-drug delivery into prostate cancer cells. Cancer Lett. 2017;408:164-73.

22. Hühn J, et al. Selected standard protocols for the synthesis, phase transfer and characterization of inorganic colloidal nanoparticles. Chem Mater 2017:29:399-461.

23. Beija M, et al. Control of the catalytic properties and directed assembly on surfaces of MADIX/RAFT polymer-coated gold nanoparticles by tuning polymeric shell charge. J Mater Chem. 2010;20:9433.
24. Zhang Z, Liu Y, Jarreau C, Welch MJ, Taylor JSA. Nucleic acid-directed selfassembly of multifunctional gold nanoparticle imaging agents. Biomater Sci. 2013:1:1055-64

25. Manson J, Kumar D, Meenan BJ, Dixon D. Polyethylene glycol functionalized gold nanoparticles: the influence of capping density on stability in various media. Gold Bull. 2011:44:99-105.

26. Assadi A, et al. Novel chlorambucil-conjugated anionic linear-globular PEG-based second-generation dendrimer: in vitro/in vivo improved anticancer activity. OncoTargets Ther. 2016:9:5531-43.

27. Khan I, et al. Biodegradable nano-architectural PEGylated approach for the improved stability and anticancer efficacy of bendamustine. Int J Biol Macromol. 2016;92:1242-51.

28. Ajazuddin, Alexander A, Amarji B, Kanaujia P. Synthesis, characterization and in vitro studies of pegylated melphalan conjugates. Drug Dev Ind Pharm. 2013;39:1053-62.

29. Omidfar K, Daneshpour M. Advances in phage display technology for drug discovery. Expert Opin Drug Discov. 2015;10:651-69.

30. Wang $Y$, et al. Peptide-drug conjugates as effective prodrug strategies for targeted delivery. Adv Drug Deliv Rev. 2017;110-111:112-26.

31. Arimany-Nardi C, et al. Human organic cation transporter 1 (hOCT1) as a mediator of bendamustine uptake and cytotoxicity in chronic lymphocytic leukemia (CLL) cells. Pharmacogenomics J. 2015;15:363-71.

32. Gupta S, et al. Human organic cation transporter 1 is expressed in lymphoma cells and increases susceptibility to irinotecan and paclitaxel. J Pharmacol Exp Ther. 2012;341:16-23.

33. Hill BT. Studies on the transport and cellular distribution of chlorambucil in the yoshida ascites sarcoma. Biochem Pharmacol. 1972:21:495-502.

34. Asher Begletter G, Goldenberg J. Uptake and decomposition of chlorambucil by L5178y lymphoblasts in vitro. Biochem Pharmacol. 1983;32:535-9.

35. Uchino $\mathrm{H}$, et al. Transport of amino acid-related compounds mediated by L-type amino acid transporter 1 (LAT1): insights into the mechanisms of substrate recognition. Mol Pharmacol. 2002;61:729-37.

36. Hayashi K, Anzai N. Novel therapeutic approaches targeting L-type amino acid transporters for cancer treatment. World J Gastrointest Oncol. 2017;9:21.

37. Keating MJ, Bach C, Yesothan U, Kirkpatrick P. Bendamustine. Nat Rev Drug Discov. 2008;7:473-4.

38. KnaufWU, et al. Bendamustine compared with chlorambucil in previously untreated patients with chronic lymphocytic leukaemia: updated results of a randomized phase III trial. Br J Haematol. 2012;159:67-77.

39. Leoni LM, et al. Bendamustine (Treanda) displays a distinct pattern of cytotoxicity and unique mechanistic features compared with other alkylating agents. Clin Cancer Res. 2008;14:309-17.

40. Ehrsson H, Eksborg S, Wallin I, Nilsson S-O. Degradation of chlorambucil in aqueous solution. J Pharm Sci. 1980;69:1091-4.

41. Gilad Y, Firer M, Gellerman G. Recent Innovations in peptide based targeted drug delivery to cancer cells. Biomedicines. 2016:4:11.

\section{Submit your next manuscript to BioMed Central and we will help you at every step:}

- We accept pre-submission inquiries

- Our selector tool helps you to find the most relevant journal

- We provide round the clock customer support

- Convenient online submission

- Thorough peer review

- Inclusion in PubMed and all major indexing services

- Maximum visibility for your research

Submit your manuscript at www.biomedcentral com/submit 